
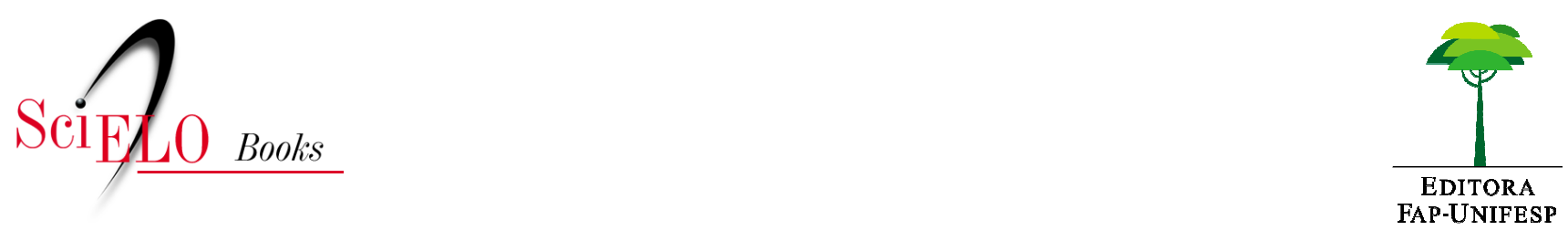

\title{
5 - O plano político pedagógico do curso de medicina \\ um processo em permanente construção
}

\author{
Rosana Fiorini Puccini \\ Miguel Roberto Jorge
}

\section{SciELO Books / SciELO Livros / SciELO Libros}

PACCINI, RF., and JORGE, MR. O plano político pedagógico do curso de medicina: um processo em permanente construção. In PUCCINI, RF., SAMPAIO, LO., and BATISTA, NA., orgs. A formação médica na Unifesp: excelência e compromisso social [online]. São Paulo: Editora Unifesp, 2008. pp. 119-159. ISBN 978-85-61673-66-6. Available from SciELO Books <http://books.scielo.org >.

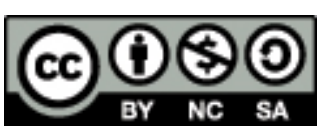

All the contents of this work, except where otherwise noted, is licensed under a Creative Commons Attribution-Non Commercial-ShareAlike 3.0 Unported.

Todo o conteúdo deste trabalho, exceto quando houver ressalva, é publicado sob a licença Creative Commons Atribuição Uso Não Comercial - Partilha nos Mesmos Termos 3.0 Não adaptada.

Todo el contenido de esta obra, excepto donde se indique lo contrario, está bajo licencia de la licencia Creative Commons Reconocimento-NoComercial-CompartirIgual 3.0 Unported. 


\section{II \\ A FORMAÇÃO MÉDICA NA UNIFESP \\ Proposta Atual}




\title{
5 \\ O Plano Político Pedagógico do Curso de Medicina: \\ Um Processo em Permanente Construção
}

\author{
Rosana Fiorini Puccini e \\ Miguel Roberto Jorge
}

INTRODUÇÃO

O atual currículo do curso de Medicina da Unifesp resulta de uma longa trajetória de quase 75 anos. Inclui dedicação, compromisso com o ensino e, sobretudo, capacidade de agregar profissionais com grande vocação para o ensino de graduação e pós-graduação lato e stricto sensu, pesquisa e extensão, esta última representada não somente por sua atuação no hospital universitário, mas também, na assistência em diferentes níveis de atenção à saúde e envolvimento em programas e projetos comunitários. As mudanças curriculares do curso de $\mathrm{Me}$ dicina têm ocorrido de forma articulada aos diferentes contextos da própria instituição e do país - políticos, históricos, culturais e de organização e conquistas de nossa sociedade. Cabe destacar, nesse processo, o papel da estruturaçáo dos serviços de saúde e as mudanças mais profundas a partir da criação do Sistema Único de Saúde (sUs) em I988, em especial, a garantia da saúde como direito e o controle 
social. Neste capítulo, serão abordados o processo de construção do atual currículo de medicina da Unifesp, o currículo vigente e aspectos relacionados à gestáo e avaliação do curso.

\section{O PROCESSO DE CONSTRUÇÃO}

DO ATUAL CURRÍCULO DE MEDICINA DA UNIFESP

A reformulação do currículo que resultou na implantação do atual modelo começou a ser construída com a aprovaçáo no Conselho Departamental, da entáo Escola Paulista de Medicina (EPM), do projeto "A Graduaçáo Médica - Uma Proposta de Avaliação", em I 987. O objetivo principal foi desenvolver um trabalho que considerasse a contribuição de todos os segmentos da instituição - docentes, alunos e egressos. As idéias centrais foram extraídas de consolidados pareceres, elaborados por grupos de discussão, constituídos por representantes dos diferentes departamentos, alunos e residentes. A busca pela inovação, o acompanhamento atento das tendências nacionais e internacionais (World, I988; Chaves \& Rosa, I990; Feuerwerker, 2006) e a participação ativa dos dirigentes do curso de Medicina junto a entidades de ensino médico, incluindo a adesão da EPM à avaliação proposta pela Comissão Interinstitucional Nacional de Avaliação do Ensino Médico (Cinaem, I999; Siqueira, 2006), contribuíram, também, para o processo de reformulação e, em 1997, tem início o Currículo Nuclear, o qual apresenta como princípios gerais:

- Integração de disciplinas: construção do currículo com base em conteúdos e não em disciplinas administrativas, buscando reduzir a fragmentação. Algumas disciplinas que permaneceram têm buscado atuar de forma articulada a outras unidades curriculares visando a estabelecer relações, sobretudo com a clínica. 
- Integração básico-clínica: assumindo esta articulação como desafio a ser superado de forma processual, a participação de docentes oriundos das ciências biológicas e clínicas em alguns módulos tem buscado superar a dicotomia básico/profissional tão comum na formação em saúde.

- Início de atividades práticas, compatíveis com sua competência, desde a primeira série do curso: ao contrário da organização curricular tradicional, o graduando exercita sua prática desde o início do curso, possibilitando autonomia crescente no exercício de suas atividades.

- Atuação em diferentes cenários da prática profissional: hospital universitário, ambulatórios, unidades básicas de saúde e na comunidade; esses variados contextos de aprendizagem têm buscado superar o modelo hospitalocêntrico de formação possibilitando ao graduando formar-se para atuar na promoção, proteção e recuperação da saúde.

- Estratégias pedagógicas que favoreçam a auto-aprendizagem: procura-se motivar os estudantes para a busca ativa de informaçóes e a aprendizagem em contexto da prática profissional com uma perspectiva problematizadora. A organização nuclear do currículo, com pequenos grupos de alunos permite uma formação mais individualizada, propiciando a responsabilidade crescente do graduando com seu processo de formação.

- Tempo pró-aluno: valorizam-se espaços na organização curricular para que os estudantes possam dedicar-se a atividades de estudo, reflexão ou lazer.

- Disciplinas eletivas: pretende uma formação diferenciada a partir do interesse do graduando de forma a propiciar o aprofundamento e/ou a atualização do conhecimento teórico-prático em áreas de maior interesse do aluno. Anualmente professores de diferentes áreas oferecem disciplinas de 16 a 32 horas, abordando conteúdos que não constem do currículo obrigatório e possam ampliar 
a visão do estudante em relação ao tema em si e às possibilidades de atuação profissional.

O curso foi estruturado tomando como pressupostos a importância de aspectos formativos e informativos, para que o estudante aprenda a aprender, aprenda a fazer, aprenda a conviver e aprenda a ser. Com esta perspectiva, é esperado que o médico formado pela Unifesp-EPM apresente o seguinte perfil:

- Conhecimento das bases morfológicas e fisiológicas da medicina.

- Conhecimento das bases da medicina celular e molecular.

- Conhecimento da estrutura e função de órgãos, sistemas e aparelhos, que permita acompanhar processos fisiológicos e de doença.

- Entendimento crítico de princípios diagnósticos e terapêuticos que possibilitem o exercício profissional baseado na evidência médico-científica.

- Competência para diagnosticar, tratar e orientar portadores das doenças mais prevalentes, reconhecendo os limites de sua ação.

- Habilidades básicas de sua profissão.

- Competência para o desempenho ético da profissão.

- Compreensão das dimensôes biológica, psicológica e social no processo saúde-doença.

- Conhecimentos básicos de promoção de saúde e prevenção de doenças.

- Capacidade para o trabalho em equipe multiprofissional e interdisciplinar.

- Conhecimento do método científico.

A educação profissional iniciada no curso de graduação deve ser continuada e, portanto, os graduados devem estar preparados para múltiplas possibilidades que se abrem após a conclusão do curso: 
exercício profissional em grandes áreas e especialidades, pesquisa, carreira acadêmica. Os profissionais formados devem ter conhecimento da organização do sistema de saúde vigente no país, das características do mercado de trabalho e estar preparados para trabalhar em equipe. O currículo do Curso Médico na Unifesp tem sido continuadamente avaliado e aprimorado, refletindo as principais características da instituição: integração científica e geográfica entre as áreas biológicas e profissionais; corpo docente com elevado nível de titulação acadêmica e regime de trabalho de tempo integral em porcentagem superior a 95\%; atividade de grupos de excelência em pesquisa; significativo envolvimento de estudantes em programas de iniciação científica, e participação de estudantes em açóes externas ao campus.

Em 200 I, teve início um amplo processo de avaliação do Currículo Nuclear, o qual teve como marco uma oficina que reuniu mais de cem pessoas entre docentes, discentes, pós-graduandos e residentes. Nessa oficina, na qual foram reafirmadas as principais metas e estratégias do Currículo Nuclear, foram revistos alguns pontos estabelecidos anteriormente, identificados obstáculos para sua execução e apresentadas propostas visando à superação de dificuldades. Os aspectos positivos e negativos do Currículo foram apontados e discutidos e adequaçóes pertinentes propostas e aprovadas em todas as instâncias da instituição, sempre considerando a realidade e características próprias da Unifesp. Os desdobramentos e decisóes dessa oficina foram favorecidos e impulsionados com a publicação das diretrizes curriculares nacionais para os cursos de medicina (Brasil, 200I) e com a aprovação do Promed (Brasil, 2002), no ano seguinte. A concordância entre as propostas estabelecidas nessa oficina para o aprimoramento do Currículo Nuclear da Unifesp, as Diretrizes Curriculares e o Promed (plano detalhado apresentado no capítulo 3) favoreceram muito o processo de mudança na instituição. Recentemente, a aprovação do Pró-Saúde veio somar-se ao conjunto de ações desenvolvidas em função do Promed e do movimento de 
reestruturação do curso, definitivamente incorporado na universidade. $\mathrm{O}$ processo de elaboração do atual plano político pedagógico do curso de Medicina da Unifesp foi conduzido pela Comissão do Curso de Medicina, em 2005, sendo concluído em maio de 2006. Com o objetivo de que esse processo cumprisse um papel pedagógico junto aos docentes e os envolvesse na sua elaboração, foram realizadas atividades voltadas especialmente aos coordenadores de unidades curriculares, visando a orientá-los na elaboração dos planos de ensino, contando-se para esta atividade com assessoria pedagógica. Posteriormente, foi feita reorientação desse trabalho e, finalmente, conclusão e aprovação do plano na Comissão do Curso de Medicina.

\section{O ATUAL CURRÍCULO MÉDICO DA UNIFESP}

O curso de Medicina da Unifesp, desde 2005, oferece I I vagas pelo sistema universal e onze pelo sistema de cotas para negros ou indígenas que cursaram ensino médio exclusivamente em escola pública. Tem duração de seis anos, em período integral, com carga horária total de aproximadamente 9900 horas, sendo que da $\mathrm{I}^{\underline{a}}$ à $4^{\underline{a}}$ série, $5 \%$ da carga horária é destinada ao tempo pró-aluno e da $2^{\underline{a}}$ à $4^{\underline{a}}$ série, outros $5 \%$ da carga horária são destinados às disciplinas eletivas, as quais têm caráter obrigatório, complementar. $\mathrm{O}$ aluno pode escolher pelo menos uma disciplina por semestre (com duração de oito semanas) ou duas (com duração de quatro semanas), de um rol oferecido a ele. Outras atividades têm sido consideradas para comporem os créditos exigidos pelas disciplinas eletivas - iniciação científica e a participação em projetos de extensão, ambos mediante apresentação de relatório dos respectivos orientadores.

A estrutura rígida entre os ciclos básico e clínico foi definitivamente rompida a partir de 2003 com a implantaçáo de cinco novos 
módulos e aprimoramento de quatro outros nas duas primeiras séries, de tal forma que ocorre uma inserção em atividades práticas desde o primeiro semestre do curso. Além disso, módulos das áreas biológicas que já vinham desenvolvendo atividades buscando estabelecer correlaçôes com a área clínica puderam implementar esse processo, considerando que esta discussão encontrava-se cada vez mais presente nas comissóes, sub-comissóes, oficinas e seminários. Por outro lado, a participação de professores das áreas clínicas nos primeiros semestres do Curso Médico e o contato com alunos das primeiras séries com suas expectativas e em processo de construção do que é ser médico trouxeram motivação e favoreceram a reflexão para as atividades específicas desenvolvidas por esses professores em momentos posteriores do curso, como, por exemplo, no Internato.

A seguir apresentamos as principais características de cada uma das séries do atual currículo do curso de Medicina da Unifesp. No quadro I, encontra-se a relação das unidades curriculares obrigatórias, com suas respectivas ementas e cargas horárias. Neste quadro, não foram consideradas as cargas horárias de plantóes e as atividades de finais de semana, com o objetivo de permitir comparaçóes entre as unidades quanto à duração. No quadro 2, encontra-se a lista de disciplinas eletivas do ano 2007. 
QUADRO I. Unidades curriculares do curso de Medicina da Unifesp em 2006 com ementas e carga horária TOTAL (C.H.)

Unidades Curriculares [Módulos]

Áreas

Ementas

C.H.

\section{PRIMEIRA SÉRIE}

Observação de

práticas médicas

Clínica; Cirurgia; Pediatria;

Psiquiatria; Ginecologia;

Obstetrícia; Saúde Coletiva;

Biológicas; Oftalmologia

Observação e análise da prática médica nos diferentes níveis do complexidade dos serviços públicos de saúde. Relação médico-paciente. Condições socioeconômicas da população e saúde. Trabalho em equipe multidisciplinar.

Bases morfológicas da medicina

Organização funcional do corpo humano: das células aos sistemas

Saúde coletiva: política de saúde no Brasil e o Sistema Único de Saúde (sus)
Anatomia; Fisiologia; Biologia do Desenvolvimento

Morfologia geral do corpo humano em três vertentes (anatômicas, histológicas e de desenvolvimento) e correlação com disciplinas básicas e clínicas.

Estrutura e função de compostos biológicos da célula, degradação e biossíntese desses compostos em diferentes tecidos e órgãos, suas características biofísicas e suas funções fisiológicas.

Conceito de saúde e problema de saúde. Direito social à saúde. Política de saúde no Brasil. sus. Organização dos serviços de saúde. Planejamento em saúde. Sistemas nacionais de saúde em outros países. Mercado de trabalho.

\section{Saúde Coletiva}


Suporte básico de vida no adulto e na criança e primeiros socorros

Introdução às técnicas básicas nos cuidados em saúde

Psicologia médica I
Pediatria; Clínica;

Enfermagem

Enfermagem

Psicologia Médica

Biologia Molecular Microbiologia

Imunologia

Parasitologia
O atendimento das emergências no Estado de São Paulo. Atendimento primário a emergências clínicas e traumáticas. Suporte básico de vida no lactente, pré-escolar, escolar e adulto. Primeiros socorros.

Noçōes básicas de biossegurança. Relacionamento interpessoal. Controle de sinais vitais. Curativos. Medicação por via parenteral.

Relações humanas. Reconhecimento e manejo das características das pessoas e da dinâmica das relaçóes para aplicação no campo da atenção em saúde.

TOTAL I ${ }^{a}$ SÉRIE

\section{SEGUNDA SÉRIE}

Bases moleculares e celulares da medicina
Mecanismos moleculares de processos biológicos fundamentais (fluxo de informação gênica, síntese/ degradação/tráfego de macromoléculas, proliferação e morte celular, transformação maligna, hemostasia). Mecanismos moleculares e celulares da relação parasita-hospedeiro. Mecanismos de defesa do organismo. 


$\begin{array}{lll}\begin{array}{l}\text { Unidades Curriculares } \\ \text { [Módulos] }\end{array} & \text { Áreas } & \text { Ementas } \\ \text { Epidemiologia I } & \text { Epidemiologia } & \begin{array}{l}\text { Indicadores de condiçóes de vida e de saúde. Mor- } \\ \text { talidade. Morbidade. Transiçáo demográfica e epi- } \\ \text { demiológica. Fontes de informaçáo. Causalidade. }\end{array} \\ & \begin{array}{l}\text { História natural das doenças. Promoçáo da saúde } \\ \text { e níveis de prevençáo. Desigualdades em saúde. O } \\ \text { método epidemiológico. }\end{array}\end{array}$

Bioestatística

Bioestatística
Sociologia

Educação em Saúde;
Definição de Bioestatística. Etapas do método científico. Planejamento de experimentos e amostragem. Tipos de variáveis geradoras de dados. Estatística descritiva e inferencial.

O modelo biomédico de conhecimento. Processo saúde-doença. Causalidade na ciência e na medicina. Serviços de saúde no Brasil. Mercado de trabalho. Prática médica e prática social.

Práticas educomunicativas em saúde. Comunicação do médico com o paciente, com a equipe de trabalho e com a comunidade. A comunicaçáo e a aderência do paciente ao tratamento. A função educativa do médico.

\author{
Saúde Coletiva \\ na prática do médico
}




\section{Atendimento pré- \\ hospitalar do trauma \\ Cirurgia Torácica e \\ Emergências}

Psicologia médica II

Psicobiologia e

farmacologia

Psicologia Médica
Psicobiologia; Farmacologia

Anatomia patológica $\quad$ Patologia
Semiologia integrada $\quad \begin{aligned} & \text { Clínica; Pediatria; } \\ & \text { Obstetrícia; Ginecologia; } \\ & \text { Psicologia Médica }\end{aligned}$

Sistema de resgate. Mecanismos de trauma. Avaliação do local do trauma e medidas preventivas. Imobilização. Triagem em áreas de catástrofe. Salvamentos.

A entrevista médica. Formação da personalidade. Aparelho psíquico e mecanismos de defesa. Comunicação. Emoçóes. A equipe multiprofissional.

Conceitos de Farmacologia Geral. Mecanismo de ação de drogas e Farmacocinética. Farmacologia por sistemas e aparelhos. Conceito de Psicobiologia. Funcionamento cognitivo e comportamental. Medicina e biologia do sono. Medicina e sociologia do abuso de drogas.

Processos patológicos gerais. Processos degenerativos. Distúrbios circulatórios. Agressão. Defesa e adaptação do organismo. Ciclo celular. Neoplasias e carcinogênese.

Anamnese integral por ciclos de vida - Clínica Médica, Pediatria, Ginecologia, Obstetrícia e Geriatria. O processo do adoecer - aspectos físicos, psicológicos e sociais. 


\begin{tabular}{|c|c|c|}
\hline $\begin{array}{l}\text { Unidades Curriculares } \\
\text { [Módulos] } \\
\text { TERCEIRA SÉRIE }\end{array}$ & Areas & Ementas \\
\hline Semiologia humana & $\begin{array}{l}\text { Clínica; Pediatria; } \\
\text { Psicologia Médica; Nutrição; } \\
\text { Diagnóstico por Imagem; } \\
\text { Informática em Saúde }\end{array}$ & $\begin{array}{l}\text { Semiologia do adulto, criança e adolescente. Assis- } \\
\text { tência ao adulto, à criança e ao adolescente no seu } \\
\text { contexto emocional, familiar, social e cultural. } \\
\text { Exames subsidiários. Avaliaçáo nutricional. Infor- } \\
\text { mática médica. Conceitos básicos de diagnóstico } \\
\text { por imagem. }\end{array}$ \\
\hline $\begin{array}{l}\text { Anatomia topográfica } \\
\text { aplicada }\end{array}$ & Anatomia & $\begin{array}{l}\text { Fundamentos da anatomia topográfica. Divisão regio- } \\
\text { nal do corpo humano. Correlação anátomo-clínica. } \\
\text { Técnicas de dissecação e utilizaçaáo de instrumentais. }\end{array}$ \\
\hline $\begin{array}{l}\text { Fundamentos de } \\
\text { oncologia }\end{array}$ & Clínica/Oncologia & $\begin{array}{l}\text { Conceitos básicos de oncologia. Biologia molecu- } \\
\text { lar em oncologia. Anatomia patológica do câncer. } \\
\text { Epidemiologia do câncer no Brasil e no mundo. } \\
\text { Prevençáo. Marcadores. Estadiamento. }\end{array}$ \\
\hline Epidemiologia II & Saúde Coletiva & $\begin{array}{l}\text { Estratégias e ações de promoção de saúde e de } \\
\text { prevençấo para indivíduos (medicina clínica indi- } \\
\text { vidual) e para a população geral (saúde coletiva). } \\
\text { Epidemiologia das doenças crônicas transmissíveis } \\
\text { e não-transmissíveis. Vigilância epidemiológica. Ti- } \\
\text { pos de estudos. }\end{array}$ \\
\hline
\end{tabular}




\section{Genética médica}

Psiquiatria
Doenças infecciosas

\section{Genética}

Psiquiatria

Técnica operatória e Cirurgia
cirurgia experimental

Infectologia Clínica e Pediátrica
Fundamentos da genética médica básica. Desenvolvimento do raciocínio genético clínico com a aplicação da propedêutica da especialidade. Estratégias de intervenção visando à prevenção primária, secundária e terciária das doenças genéticas.

História da Psiquiatria. Transtornos mentais. Anamnese psiquiátrica. Psicopatologia. Psicofarmacologia e eletroconvulsoterapia.

Formação cirúrgica básica. Manobras cirúrgicas no primeiro atendimento ao politraumatizado. Microcirurgia. Cirurgia vídeo-assistida. Cicatrização. Antibioticoterapia profilática e complicações dos atos anestésicos e operatórios.

Interação hospedeiro-parasita. Imunizaçōes. Principais endemias brasileiras. Anamnese, exame clínico e diagnóstico laboratorial em doenças infecciosas. Uso de antimicrobianos. Epidemiologia hospitalar. Risco profissional. Notificação de doenças transmissíveis 


\section{Unidades Curriculares}

[Módulos]

Bioética

Bases da medicina por sistema e aparelhos:

locomotor

Bases da medicina por sistema e aparelhos: reprodutor

Bases da medicina por sistema e aparelhos: cabeça/pescoço
Áreas

Ementas

Medicina Legal; Bioética

Reumatologia Clínica e Pediátrica; Alergia e

Imunologia; Patologia; Ortopedia; Diagnóstico por Imagem

Ginecologia; Obstetrícia; Patologia; Anestesiologia; Diagnóstico por Imagem

Cirurgia Pediátrica, Plástica e Cabeça e Pescoço;

Diagnóstico Imagem;

Otorrinolaringologia; Patologia
Bases e conceito da Bioética. Origens do pensamento ético. Ética no início e fim da vida. Direitos do paciente. Ética e exercício profissional. Ética na investigação científica.

Semiologia do aparelho locomotor. Algoritmo para diagnóstico diferencial de síndromes dolorosas. Trauma. Doenças auto-imunes. Laboratório de imunologia. Reabilitação. Infecçôes no aparelho locomotor. Doenças metabólicas.

Anatomia e fisiologia do aparelho reprodutor feminino. Propedêutica da mama, do trato genital inferior. Infertilidade. Ciclo gravídico e puerperal. Exames subsidiários em ginecologia e obstetrícia.

Bases anatômicas e fisiopatológicas das afecçôes de cabeça e pescoço. Procedimentos e tratamento das afecçôes de cabeça e pescoço. 
Bases da medicina por sistema e aparelhos: hematopoiético

Hematologia Clínica e Pediátrica; Oncologia Clínica e Pediátrica; Patologia

Oftalmologia

Oftalmologia

Anestesiologia

Anestesiologia

Geriatria

Clínica
Hematopoiese. Propedêutica clínica e laboratorial em Hematologia. Anemias. Hipoplasias medulares. Síndromes mieloproliferativas. Leucemias e linfomas. Coagulação e coagulopatias. Transfusão sanguínea. Imunohematologia.

TOTAL $3^{\underline{a}}$ SÉRIE

Anatomia ocular. Processos fisiológicos relacionados à visão. Manifestaçóes oculares com disfunçóes sistêmicas. Doenças oculares mais freqüentes. Sinais e sintomas em oftalmologia.

Áreas de atuação da anestesiologia. Cuidados pré, intra e pós-operatório. Dor aguda e crônica. Analgesia e sedação. Anestesia geral e local. Distúrbio eletrolítico e ácido-básico.

Envelhecimento e suas repercussões. O trabalho da equipe multi e interdisciplinar na atenção ao idoso. Avaliação geriátrica global. Desenvolvimento da anamnese e exame físico multiprofissional. Diagnóstico diferencial em geriatria. 


\begin{tabular}{|c|c|c|c|}
\hline $\begin{array}{l}\text { Unidades Curriculares } \\
\text { [Módulos] }\end{array}$ & Áreas & Ementas & $\begin{array}{l}\text { C.H. } \\
\text { [horas] }\end{array}$ \\
\hline $\begin{array}{l}\text { Medicina legal e } \\
\text { deontologia }\end{array}$ & Medicina Legal; Bioética & $\begin{array}{l}\text { Introdução à medicina legal. Identidade por } \\
\text { meios biológicos (antropométricos, médicos, la- } \\
\text { boratoriais). Identificação judiciária. Asfixias mé- } \\
\text { dico-legais. Estudo da fisiopatologia das alteraçóes } \\
\text { da dinâmica respiratória e das modificaçôes do } \\
\text { meio ambiente. }\end{array}$ & 20 \\
\hline $\begin{array}{l}\text { Medicina de urgência } \\
\text { baseada em evidência }\end{array}$ & Clínica & $\begin{array}{l}\text { Doenças freqüentes na clínica do adulto. Medicina } \\
\text { baseada em evidência. }\end{array}$ & 45 \\
\hline $\begin{array}{l}\text { Bases da medicina por } \\
\text { sistema e aparelhos: } \\
\text { digestório }\end{array}$ & $\begin{array}{l}\text { Gastroenterologia Clínica e } \\
\text { Pediátrica; Gastroenterologia } \\
\text { Cirúrgica; Cirurgia Pediá- } \\
\text { trica; Patologia; Anatomia; } \\
\text { Diagnóstico por Imagem }\end{array}$ & $\begin{array}{l}\text { Doenças do esôfago, estômago, duodeno, pâncreas, } \\
\text { vias biliares, fígado, intestinos delgado e grosso, ânus } \\
\text { e paredes abdominais em adultos e crianças. Infor- } \\
\text { maçốes básicas sobre principais doenças do trato di- } \\
\text { gestório e órgãos anexos (fígado e pâncreas). }\end{array}$ & 160 \\
\hline $\begin{array}{l}\text { Bases da medicina por } \\
\text { sistema e aparelhos: } \\
\text { urinário }\end{array}$ & $\begin{array}{l}\text { Nefrologia Clínica e } \\
\text { Pediátrica; Urologia; } \\
\text { Cirurgia Pediátrica; } \\
\text { Diagnóstico por Imagem; } \\
\text { Patologia }\end{array}$ & $\begin{array}{l}\text { Semiologia urológica. Anatomia, embriologia e } \\
\text { fisiologia do trato urinário. Anomalias congênitas } \\
\text { Infecçốes e inflamaçôes do trato genital. Litíase } \\
\text { urinária. Oncologia urológica. Trauma e urgências. } \\
\text { Doenças da próstata. Disfunçôes urinárias e sexual. } \\
\text { Exames de imagem do trato genito-urinário e adre- } \\
\text { nais. Hipertensão arterial. Glomerulopatias. Insufi- } \\
\text { ciência renal aguda e crônica. }\end{array}$ & I I 5 \\
\hline
\end{tabular}


Bases da medicina por sistema e aparelhos: respiratório

Bases da medicina por sistema e aparelhos: nervoso

Bases da medicina por sistema e aparelhos: cárdio-circulatório

Bases da medicina por sistema e aparelhos: tegumentar
Pneumologia Clínica e Pediátrica; Cirurgia Torácica; Anestesiologia; Patologia;

Diagnóstico por Imagem;

Otorrinolaringologia

Neurologia Clínica e

Pediátrica; Neurocirurgia;

Otorrinolaringologia;

Patologia; Diagnóstico por

Imagem

\section{Cardiologia Clínica e}

Pediátrica; Cirurgia Cárdio-

Vascular; Infectologia;

Patologia; Anestesiologia;

Diagnóstico por Imagem

Cirurgia Plástica e

Reparadora; Dermatologia; Patologia
Anamnese e exame clínico do sistema respiratório.

Fisiopatologia das principais doenças do sistema respiratório. Etiologia, diagnóstico clínico, por imagem, laboratorial e princípios terapêuticos das doenças do sistema respiratório.

Anatomia e fisiologia funcional do sistema nervoso. Técnicas de exame neurológico. Diagnóstico sindrômico, topográfico e etiológico das doenças agudas e crônicas do sistema nervoso. Exames complementares: neurofuncionais, imagem, anatomopatológicos. Noções de abordagem cirúrgica. Introdução à farmacoterapia e terapêutica das doenças do sistema nervoso.

Propedêutica cárdio-vascular. Diagnóstico e fisiopatologia das principais doenças cardíacas no adulto e na criança.

Semiologia dermatológica. Fisiologia da cicatrização. Curativos e pequenas cirurgias. Doenças infecciosas e parasitárias em Dermatologia. Doenças inflamatórias. Tratamento clínico e cirúrgico. 


\begin{tabular}{|c|c|c|c|}
\hline $\begin{array}{l}\text { Unidades Curriculares } \\
\text { [Módulos] }\end{array}$ & Areas & Ementas & $\begin{array}{l}\text { C.H. } \\
\text { [horas] }\end{array}$ \\
\hline $\begin{array}{l}\text { Saúde integral da mulher } \\
\text { e da criança }\end{array}$ & $\begin{array}{l}\text { Pediatria; Ginecologia; } \\
\text { Obstetrícia; Nutrição; Saúde } \\
\text { Coletiva; Psicologia Médica }\end{array}$ & $\begin{array}{l}\text { Assistência à saúde da criança, da mulher e à ges- } \\
\text { tante na atençáo básica à saúde. Acompanhamen- } \\
\text { to do crescimento e desenvolvimento da criança. } \\
\text { Doenças mais freqüentes em Pediatria. Programa } \\
\text { de saúde da mulher. Prevenção do câncer gine- } \\
\text { cológico e de mama. Planejamento familiar. Pré- } \\
\text { natal normal. Intercorrências mais freqüentes no } \\
\text { pré-natal. Principais problemas nutricionais. Re- } \\
\text { lação médico-paciente. A unidade básica de saúde } \\
\text { e o sus. }\end{array}$ & 160 \\
\hline Clínica médica & Clínica & $\begin{array}{l}\text { Doenças prevalentes do adulto. Fisiopatologia, } \\
\text { diagnóstico, tratamento de pacientes adultos. Re- } \\
\text { laçáo médico-paciente. O paciente e seu contexto } \\
\text { social, cultural e familiar. }\end{array}$ & 160 \\
\hline \multirow[t]{2}{*}{ Doenças infecciosas } & Infectologia & $\begin{array}{l}\text { Interação hospedeiro-parasita. Imunizaçoes. Prin- } \\
\text { cipais endemias brasileiras. Anamnese e exame } \\
\text { clínico em doenças infecciosas. Diagnóstico labora- } \\
\text { torial. Uso de antimicrobianos. Epidemiologia hos- } \\
\text { pitalar. Risco profissional. Notificação de doenças } \\
\text { transmissíveis. }\end{array}$ & 40 \\
\hline & & TOTAL $4^{\underline{a}}$ SÉRIE & I 436 \\
\hline
\end{tabular}




\section{QUINTA SÉRIE}

Cardiologia/cirurgia

cárdio-vascular

Cardiologia Clínica;

Cirurgia Cárdio-vascular

Endocrinologia Endocrinologia

Gastroclínica/

gastrocirurgia

Hematologia

Hematologia

Nefrologia/urologia
Nefrologia; Urologia
Doenças cárdio-vasculares no adulto. Diagnóstico clínico e laboratorial das doenças cárdio-vasculares mais freqüentes. Tratamento das doenças do sistema cárdio-vascular.

Fisiopatologia, diagnóstico e tratamento das principais endocrinopatias. Diabetes Mellitus. Doenças da tireóide, paratireóide e hipófise. Distúrbios metabólicos.

Gastroclínica; Gastrocirurgia Fisiopatologia, diagnóstico e tratamento de doenças do sistema digestório. Laboratório e imagenologia em gastroenterologia. Tratamento cirúrgico de afecções gastroenterológicas.

Síndromes anêmicas. Imunohematologia e hemoterapia. Doenças mieloproliferativas. Doenças linfoproliferativas. Coagulopatias. Transplante de medula óssea.

Etiologia, fisiopatologia, diagnóstico e terapêutica das doenças do sistema urinário. Traumas e urgências do trato urinário. Indicaçóes cirúrgicas em doenças do trato urinário. 


\begin{tabular}{|c|c|c|c|}
\hline $\begin{array}{l}\text { Unidades Curriculares } \\
\text { [Módulos] }\end{array}$ & Áreas & Ementas & $\begin{array}{l}\text { C.H. } \\
\text { [horas] }\end{array}$ \\
\hline $\begin{array}{l}\text { Neurologia clínica/ } \\
\text { neurocirurgia }\end{array}$ & Neurologia; Neurocirurgia & $\begin{array}{l}\text { Diagnóstico sindrômico, topográfico e etiológico } \\
\text { das doenças neurológicas mais freqüentes. Exames } \\
\text { subsidiários nas neuropatias. Tumores cerebrais. } \\
\text { Emergências e urgências em neurologia. }\end{array}$ & $\mathrm{I} 20$ \\
\hline Oftalmologia & Oftalmologia & $\begin{array}{l}\text { Sinais e sintomas oculares. Diagnóstico diferencial } \\
\text { das doenças oculares mais freqüentes. Acuidade } \\
\text { visual de diferentes métodos. Trauma ocular. Ur- } \\
\text { gências e emergências em oftalmologia. Processos } \\
\text { oculares inflamatórios infecciosos e não infecciosos. } \\
\text { Saúde ocular e qualidade de vida. }\end{array}$ & 45 \\
\hline Otorrinolaringologia & Otorrinolaringologia & $\begin{array}{l}\text { Doenças otorrinolaringológicas: anatomia, fisiopa- } \\
\text { tologia, semiologia, diagnóstico, diagnóstico dife- } \\
\text { rencial, tratamento. }\end{array}$ & 75 \\
\hline $\begin{array}{l}\text { Pneumologia/cirurgia } \\
\text { torácica }\end{array}$ & $\begin{array}{l}\text { Pneumologia; Cirurgia } \\
\text { Torácica }\end{array}$ & $\begin{array}{l}\text { Doenças pulmonares agudas e crônicas. Exames } \\
\text { de apoio diagnóstico em pneumologia. Trata- } \\
\text { mento clínico e cirúrgico de doenças pulmonares } \\
\text { mais freqüentes. }\end{array}$ & I 20 \\
\hline Psiquiatria & Psiquiatria & $\begin{array}{l}\text { Diagnóstico e tratamento dos quadros psiquiátricos } \\
\text { freqüentes e aspectos psicológicos de pacientes psi- } \\
\text { quiátricos e gerais. }\end{array}$ & I 20 \\
\hline
\end{tabular}


Ambulatório de medicina Clínica; Medicina Preventiva Fisiopatologia, diagnóstico e conduta de doenças fregeral e familiar qüentes do adulto. Exames subsidiários na prática clínica. Aspectos psicossociais na prática clínica. Açóes preventivas, restitutivas e de promoção à saúde.

\section{Ambulatório}

interdisciplinar de atenção ao adulto I
Clínica; Dermatologia;

Ginecologia; Diagnóstico por Imagem; Psicologia Médica; Informática em Saúde

Ginecologia

Ginecologia/obstetrícia Ginecologia; Obstetrícia

Medicina preventiva clínica

Saúde Coletiva; Geriatria
Assistência integral à saúde do adulto. Manejo (diagnóstico, tratamento, acompanhamento) de doenças prevalentes do adulto e suas intercorrências. Busca em base de dados bibliográficos. Análise crítica de artigos científicos. Telemedicina.

Saúde da Mulher. Afecções clínicas e cirúrgicas em ginecologia. Câncer de mama e ginecológico. Climatério. Reprodução humana.

Fisiopatologia, diagnóstico e definição de condutas em ginecologia geral. Procedimentos e atos cirúrgicos em ginecologia e obstetrícia. Assistência ao parto normal e ao puerpério.

Programas de saúde pública. Doenças crônicas transmissíveis e não-transmissíveis. Atendimento ao idoso saudável e frágil. Vigilância epidemiológica. Noções de economia da saúde. Psicologia médica aplicada. 


\section{Unidades Curriculares}

[Módulos]

Pediatria geral

e comunitária/Medicina

do adolescente
Áreas

Pediatria e Medicina do

Adolescente; Informática em

Saúde

\section{Ementas}

C.H.

[horas]

Crescimento e desenvolvimento. Alimentaçáo e imunizaçôes em pediatria. Diagnóstico e tratamento de doenças agudas e crônicas prevalentes na infância e na adolescência. Programas e açôes em saúde. Fatores de risco para morbi-mortalidade em pediatria.

TOTAL $5^{\text {a }}$ SÉRIE (sem considerar plantóes e evolução clínica nos finais de semana - carga horária global 470h)

\section{SEXTA SÉRIE}

Ambulatório interdisciplinar de atenção ao adulto II

Clínica; Cirurgia; Ginecologia; Diagnóstico por Imagem; Psicologia Médica; Informática em Saúde

Obstetrícia

Obstetrícia

Infectologia
Infectologia
Doenças prevalentes do adulto. Tratamento e acompanhamento de doenças crônicas transmissíveis e não-transmissíveis. Aspectos psicossociais na determinação do processo saúde-doença. Campo de atuação do médico geral e do especialista.

Gestação de médio e alto risco. Gravidez na adolescente e na mulher com hipertensão, diabetes e cardiopatia. Exames subsidiários em obstetrícia.

Abordagem inicial do paciente, anamnese, fisiopatologia, diagnóstico e terapia das principais doenças infecto-contagiosas. 


\begin{tabular}{|c|c|c|}
\hline $\begin{array}{l}\text { Ortopedia e } \\
\text { traumatologia }\end{array}$ & Ortopedia e Traumatologia & $\begin{array}{l}\text { Propedêutica ortopédica. Crescimento e desenvol- } \\
\text { vimento ósseo. Doenças da infância do aparelho lo- } \\
\text { comotor. Traumas ortopédicos. Fraturas. Redução, } \\
\text { alongamento e fixaçáo externa de ossos. Tumores } \\
\text { ósseos. Reabilitaçáo em ortopedia. Medicina chine- } \\
\text { sa-acupuntura. }\end{array}$ \\
\hline Pediatria & $\begin{array}{l}\text { Pediatria; Pediatria Neonatal; } \\
\text { Emergências Pediátricas; } \\
\text { Cuidados Intensivos em } \\
\text { Pediatria }\end{array}$ & $\begin{array}{l}\text { Assistência à criança no ambiente hospitalar e } \\
\text { em situação de urgência e emergência. Doenças } \\
\text { freqüentes na criança que requerem internação } \\
\text { em hospital geral. Assistência ao recém-nas- } \\
\text { cido normal e patológico desde o nascimen- } \\
\text { to até a alta hospitalar. Principais doenças do } \\
\text { recém-nascido. }\end{array}$ \\
\hline $\begin{array}{l}\text { Suporte avançado } \\
\text { de vida em cardiologia }\end{array}$ & Cardiologia & $\begin{array}{l}\text { Ressuscitação cárdio-respiratória do adulto. Su- } \\
\text { porte avançado de vida no adulto. Atendimen- } \\
\text { to sistematizado de emergências e urgências no } \\
\text { adulto. }\end{array}$ \\
\hline Anestesiologia & Anestesiologia & $\begin{array}{l}\text { Cuidados pré, intra e pós-operatório. Analgesia e } \\
\text { anestesia. Assistência ao paciente crítico. Controle } \\
\text { da dor aguda e crônica. }\end{array}$ \\
\hline
\end{tabular}




\begin{tabular}{|c|c|c|c|}
\hline $\begin{array}{l}\text { Unidades Curriculares } \\
\text { [Módulos] }\end{array}$ & Areas & Ementas & $\begin{array}{l}\text { C.H. } \\
\text { [horas] }\end{array}$ \\
\hline Cirurgia plástica & Cirurgia Plástica & $\begin{array}{l}\text { Conceito, fisiopatologia, diagnóstico e tratamento } \\
\text { das doenças (agudas e crônicas) mais freqüentes de } \\
\text { pele, tecido celular subcutâneo e o tecido conjuntivo. }\end{array}$ & 53 \\
\hline Cirurgia vascular & Cirurgia Vascular & $\begin{array}{l}\text { Conceito, fisiopatologia, diagnóstico e tratamento } \\
\text { das doenças arteriais periféricas, venosas e linfáti- } \\
\text { cas, agudas e crônicas. }\end{array}$ & 52 \\
\hline Clínica & Clínica & $\begin{array}{l}\text { Fisiopatologia, diagnóstico e tratamento de doen- } \\
\text { ças prevalentes do adulto que requerem atendimen- } \\
\text { to em hospital geral }\end{array}$ & 160 \\
\hline Cirurgia & Cirurgia & $\begin{array}{l}\text { Cuidados pré, intra e pós-operatórios em cirurgia ge- } \\
\text { ral. Procedimentos cirúrgicos por sistemas e aparelhos. }\end{array}$ & 105 \\
\hline Emergências em cirurgia & Emergências Cirúrgicas & $\begin{array}{l}\text { Conceito, etopatogenia, diagnóstico e conduta ini- } \\
\text { cial nas urgências e emergências cirúrgicas. }\end{array}$ & 105 \\
\hline Medicina de urgência & Emergências Clínicas & $\begin{array}{l}\text { Fisiopatologia, diagnóstico e tratamento de doen- } \\
\text { ças do adulto em serviço de emergência. Exames } \\
\text { laboratoriais e de imagem }\end{array}$ & 160 \\
\hline \multicolumn{3}{|c|}{$\begin{array}{l}\text { TOTAL } 6^{\underline{a}} \text { SÉRIE (sem considerar plantões e } \\
\text { evoluçấo clínica nos finais de semana - carga horária global } 470 \mathrm{O} \text { ) }\end{array}$} & I 764 \\
\hline & & TOTAL DO CURSO & $888 \mathrm{I}$ \\
\hline
\end{tabular}


QUADRO 2. Relação de disciplinas eletivas de 2007 e respectivas cargas horárias

Disciplinas Eletivas - $I^{\underline{o}}$ semestre

Atividade Física, Exercício Físico e os Aspectos Psicobiológicos

Cuidados Paliativos

Desnutrição e Recuperação Nutricional: Trabalho junto à Comunidade 32

Fundamentos de Gestão e Economia para o Profissional de Saúde 32

História da Medicina

Medicina Esportiva

Medicina Laboratorial

Modelos Experimentais para Medicina: Mutantes e Transgênicos

Prevenção das Doenças Crônicas do Adulto na Infância

Procedimentos Básicos em Urologia

Terapia Gênica e Celular

Traumatologia do Esporte

Acupuntura

Acupuntura e Medicina Antroposófica em Obstetricia

Autogestão da Carreira Médica

Comportamento e Saúde: uma Introdução à Medicina Comportamental I 6

Endocrinologia da Infância e Adolescência

Engenharia Tecidual

Esquizofrenia - Ampliando Conceitos

Atualização em Doenças Neurodegenerativas

Princípios Ópticos e Físicos da Endoscopia Digestiva Moderna

Sexualidade Humana

Tabagismo

Fisiologia Renal e Termometabologia

Fitoterapia, Alimentos Funcionais, Radicais Livres e Doenças Oxidativas I 6 Intervenção Breve para Usuários de Álcool e outras Drogas I6 Introdução à Ortopedia Pediátrica e Alteraçôes Posturais na Infância I 6 Noções Básicas de Medicina Fetal 
Oncologia Pediátrica

Prática em Saúde Digital 16

Radioterapia e Radiobiologia $\quad$ I6

Uso de Drogas em Diferentes Contextos Sócio-culturais I6

Disciplinas Eletivas - $2^{0}$ semestre C.H.

Construção de Banco de Dados com Informaçóes de Saúde I6

Estresse Oxidativo em Modelos Experimentais de Doenças Inflama$\begin{array}{ll}\text { tórias e Cardiovasculares } & \text { I } 6\end{array}$

Caleidoscorpos: Corpos que Sentem e se Expressam I6

Abordagens do Conhecimento: Interdisciplinaridade e Transdisciplinaridade

Linfonodo Sentinela $\quad$ I6

Qualidade de Vida em Obstetrícia $\quad$ I6

Cuidados com Ferida Operatória $\quad$ I6

Estresse Oxidativo. Doenças e Envelhecimento. I6

Ultra-sonografia em Obstetrícia $\quad$ I6

Cidadania e Acolhimento em Saúde - Visão Interdisciplinar I6

Reabilitação nas Grandes Incapacidades $\quad$ I6

Radioterapia e Radiobiologia $\quad$ I6

Temas Práticos de Fisiologia Renal e Termometabologia I6

Estrutura Função e Inter-relação dos Tecidos Epitelial e Conjuntivo 16

Eletrocardiografia na Prática Médica $\quad$ I6

Metodologia para Solução Criativa de Problemas $\quad$ I6

$\begin{array}{ll}\text { Esquizofrenia } & \text { I6 }\end{array}$

Semiologia Avançada em Cardiologia 32

Tanatologia - Estudo da Morte 32

Curso Teórico e Prático em Medicina e Biologia do Sono 32

Introdução à Sexologia Educacional 32

Intervenções de Enfermagem no Paciente com Distúrbios Neurológicos 32

Curso de Tratamento dos Distúrbios do Sono 32 
Desnutrição e Recuperação Nutricional - Trabalho junto à Comunidade 32

Atividades Educativas na Doença Crônica 32

Saber Cuidar: Ensinando Saúde Coletiva - Aprendendo Cidadania 32

Medicina Perinatal Baseada em Evidências $\quad 32$

Oficina de Auto-Estima $\quad 32$

Espiritualidade e Medicina $\quad 32$

\section{$I^{\underline{a}}$ Série}

Nesta série há sete unidades curriculares. Uma dessas unidades, introduzida a partir de 2003 como uma das novas unidades curriculares previstas no Promed - Observação de Práticas Médicas -, tem proporcionado ao aluno a oportunidade de observar diferentes possibilidades de atuaçáo profissional e discuti-las considerando aspectos diversos: a organização do sistema de saúde, a relação médico/paciente, suas emoçóes e angústias, a vida e a morte. $\mathrm{O}$ fato de o módulo Observação de práticas médicas integrar professores e profissionais de áreas diversas (Saúde Coletiva Psicologia Médica, Clínica, Pediatria, Cirurgia, Ginecologia, Obstetrícia e Ciências Biológicas) constitui a essência desta unidade, proporcionando, sobretudo, integração entre docentes e intenso crescimento do grupo envolvido. No $2^{\circ}$ semestre desta série, a Psicologia médica I garante continuidade na discussão e aprofundamento de aspectos e questóes levantadas a partir das observaçóes das práticas médicas, agora mais elaboradas e subsidiadas conceitualmente, em especial, no que se refere às relaçóes humanas e ao conhecer pessoas (Marco, 2007).

Duas outras unidades com maior carga horária - Bases morfológicas da medicina e Organização funcional do corpo humano - são desenvolvidas durante todo o ano ( $\mathrm{I}^{\circ}$ e $2^{-}$semestres) e são abordados conteúdos das áreas biológicas de forma integrada por sistemas e aparelhos. O desenvolvimento dessas unidades é articulado de tal 
forma que as bases morfológicas de um determinado aparelho/sistema são abordadas simultaneamente à organizaçáo funcional desse mesmo aparelho/sistema. Logo, no planejamento são considerados os conteúdos semana a semana. Com o objetivo de permitir ao aluno uma aproximação com a clínica e compreender a aplicabilidade desse conhecimento para o desempenho profissional são realizados seminários e discussôes de casos clínicos. Para o preparo desses seminários o aluno é estimulado a procurar professores da respectiva área (Clínica, Cirurgia, Ginecologia, entre outros), apresentando, sempre que possível, casos ou situaçóes vivenciadas nos serviços de saúde. Esta aproximação é extremamente facilitada pela proximidade física dos departamentos das áreas biológicas (na Unifesp esses departamentos encontram-se no mesmo campus do hospital e demais departamentos das áreas profissionais) e pelo desenvolvimento simultâneo das unidades curriculares que aproximam os alunos dos serviços de saúde e professores das áreas clínicas (Observação de práticas médicas, Introdução às técnicas básicas, Saúde coletiva: políticas de saúde no Brasil e o sus). Alguns exemplos de temas abordados relacionados ao conteúdo dos módulos das áreas biológicas: reprodução assistida, anticoncepçáo, hidrocefalia, defeitos do fechamento da parede abdominal, megacolo congênito, erros inatos do metabolismo, obesidade, diabetes. Na dependência do tema, na apresentação dos seminários tem-se buscado a participação de professores de diferentes áreas Anatomia, Histologia, Bioquímica, Biologia do Desenvolvimento e professores convidados da Clínica e Cirurgia.

As unidades curriculares - Suporte básico de vida/Primeiros socorros e Introdução às técnicas básicas nos cuidados em saúde - têm o objetivo de introduzir o aluno e capacitá-lo para realização de alguns procedimentos relacionados aos cuidados de saúde. Essas unidades despertam grande interesse e colocam o aluno mais próximo de prática profissional. $\mathrm{Na}$ unidade de Introdução às técnicas básicas aos cuidados de saúde os alunos têm, ainda, a possibilidade de 
atuar em unidades básicas e realizar atendimento de pacientes (sinais vitais, curativos, aplicação de medicamentos), sempre sob supervisão docente, de tal forma que ele tem a oportunidade de vivenciar situaçóes de aprendizado relacionadas à assistência às pessoas e ao trabalho em equipe - como se relacionar, como se dirigir ao paciente, como orientar. Deve-se destacar que, simultaneamente, questóes como relaçóes entre pessoas, sofrimento, papel profissional, estão sendo abordadas na Psicologia médica I, tornando essas vivências bastante enriquecedoras. Ao mesmo tempo, a unidade curricular Saúde coletiva: políticas de saúde no Brasil e o sus - procura ampliar a visão do aluno em relaçáo ao papel e atribuiçóes dos serviços públicos, contextualizando, politicamente, o papel da unidade na qual ele está atuando. Essa unidade curricular vem apresentando mudanças desde sua implantação em I999 e, a partir de 2007, conta com importante reformulação buscando maior vinculação dos alunos/unidade básica, continuidade e integraçáo com a equipe de saúde dos serviços de saúde. Essa reformulação inclui a integração com demais áreas do campo da saúde coletiva - Epidemiologia, Bioestatística, Sociologia Médica.

\section{$2^{\underline{a}}$ Série}

Nesta série, constituída por dez unidades curriculares, há uma ampliação das atividades práticas junto aos pacientes - Educação e comunicação na prática do médico, Psicologia médica II, Semiologia integrada por ciclos de vida. Com esta última unidade, foi introduzido o ensino da propedêutica com foco na anamnese, desenvolvida por professores da psicologia médica e das áreas clínicas correspondentes, buscando romper com a dicotomia corpo/mente, freqüentemente acentuada durante o aprendizado da semiologia. Mais uma vez, em todas essas unidades há necessidade de articulação entre professores de diferentes áreas e vivências nos serviços de saúde, o que tem pro- 
porcionado crescente processo de integração entre disciplinas e departamentos, favorecendo as mudanças e o aprimoramento curricular. A unidade curricular - Atendimento pré-hospitalar ao trauma - foi introduzida em 2004, como continuidade ao ensino da emergência iniciado na $\mathrm{I}^{\mathrm{a}}$ série, situação esta de grande relevância e presente em regióes metropolitanas, despertando grande interesse dos alunos.

As unidades de epidemiologia, bioestatística e sociologia médica encontram-se em processo de reformulação e passam a integrar o módulo da I $\underline{\underline{a}}$ série (em 2007), com continuidade na $2^{2}$ série (2008) e no decorrer do curso, incluindo o Internato. Como componente essencial dessa reformulação, os estudantes deverão desenvolver atividades práticas nas unidades básicas de saúde, buscando garantir vínculo ao serviço de saúde e à equipe.

A unidade curricular - Bases moleculares e celulares da medicina - com maior carga horária desta série, desenvolve-se articuladamente e integradamente, buscando sempre estabelecer relaçóes entre as áreas envolvidas (Microbiologia, Imunologia, Parasitologia e Biologia Molecular), o que inclui a avaliação. Esta ocorre de forma contínua no decorrer do módulo, o qual se desenvolve no Io semestre. A abordagem de temas clínicos tem sido progressivamente introduzida, destacando-se os seminários preparados e apresentados pelos alunos, abordando e estabelecendo relaçôes entre os conteúdos de todas as disciplinas participantes da unidade curricular. Alguns exemplos de temas abordados: envelhecimento, angiogênese, malária, tuberculose, sepse, lupus eritematoso sistêmico, diabetes.

A Anatomia patológica aborda, nesse momento, os fundamentos da área, os quais irão subsidiar toda a compreensão dos processos patológicos. A Psicobiologia e a Farmacologia não estão organizadas e integradas a módulos e tem sido discutida a possibilidade de parte de seus conteúdos se articularem em séries com maior atuação clínica, sobretudo no que se refere à farmacologia. 


\section{$3^{\underline{a}}$ Série}

Nesta série, constituída por treze unidades curriculares, há predomínio de atividades práticas de assistência a pacientes, com destaque à unidade curricular de Semiologia humana. Esta unidade, desde sua criação no atual formato envolvendo seis disciplinas (I 999), tem buscado vencer dois grandes desafios: I) integrar diferentes disciplinas e departamentos separados do ponto de vista administrativo e 2) agregar, formar um grupo de professores comprometidos com o ensino da propedêutica, na medida em que a escola médica, hoje, tem sua estrutura embasada nas especialidades e o ensino da semiologia requer uma abordagem e conhecimento global, representando, portanto, uma atuação do professor para além da sua prática, prioritariamente inserida nas disciplinas e com foco na especialidade. Esse processo de construção de um pensar mais articulado incluiu a realização de seminários, elaboração conjunta de material didático, elaboração de roteiro e critérios mais uniformes e sistematizados de avaliação, interação com as especialidades clínicas e pediátricas visando a estabelecer uma linguagem comum. Requer encontros e reprogramação de forma continuada. A Anatomia topográfica, hoje não integrada a este módulo, é uma das unidades curriculares, juntamente com a Técnica operatória, que poderiam se articular e contribuir no processo de ensinoaprendizagem da semiologia. Estas duas unidades mantêm expressiva atividade prática e proximidade com as áreas clínicas.

A Genética médica, embora não integrada a módulo, apresenta importante componente clínico e por esse motivo se desenvolve nessa série, em que os alunos têm maior domínio da semiologia. A Epidemiologia deverá se inserir na reformulação da Saúde coletiva como um todo. A Bioética, Doenças infecciosas e Fundamentos em oncologia são unidades curriculares com grande potencial de integração - com áreas clínicas e biológicas, processo a ser desencadeado proximamente. 
A partir do $2^{\circ}$ semestre da $3^{\underline{a}}$ série, têm início os módulos integrados por sistemas e aparelhos que se mantêm até o final da $4^{\underline{a}}$ série. Com duração entre quatro e cinco semanas, esses módulos integram as seguintes áreas: Clínica do adulto e pediátrica, Cirurgia do adulto e pediátrica, Diagnóstico por Imagem e laboratorial e Anatomia Patológica. $\mathrm{Na} 3^{\underline{a}}$ série, os alunos estão divididos em grupos de 25 e, na $4^{\underline{a}}$ série, em grupos de quinze alunos. Esse formato permite o desenvolvimento de atividades práticas, a diversificação de cenários e utilização de técnicas de ensino-aprendizagem que instigam o aluno na busca de informaçóes. Essas técnicas, dentre elas a aprendizagem baseada em problemas, mapas conceituais, têm sido utilizadas de forma diversificada nos módulos. Quanto aos cenários - unidades básicas de saúde, laboratório de habilidades -, sua utilização constitui um processo de aprendizagem também para o professor e isso vem ocorrendo progressivamente, desde a criação do laboratório de habilidades da Unifesp em 2002.

Dois módulos da $4^{\underline{a}}$ série apresentam uma abordagem geral (não por sistemas e aparelhos) - Atenção integral à saúde da mulher e da criança e Clínica médica. A Atenção integral à saúde da mulher e da criança agrega as seguintes áreas: Pediatria, Ginecologia, Obstetrícia, Psicologia Médica, Nutrição e Saúde Coletiva/Ciências Humanas. Tem como objetivo principal a inserção do aluno na atenção básica nas áreas de atenção à mulher, gestante e criança. As atividades práticas são desenvolvidas em uma unidade da Secretaria de Estado da Saúde - cs Lívio Amato-Vila Mariana - que apresenta característica mista: ambulatório de especialidades e unidade de atenção básica à saúde. Nos anos de 1998 e I999, foi desenvolvida, também, assistência ao adulto como parte das atividades práticas do módulo de Clínica médica, permitindo, assim, uma discussão mais ampla referente ao papel e inserção no sistema de saúde desse nível de atenção em todas as áreas. Posteriormente, algumas dificuldades restringiram essas açôes no cs Lívio Amato-Vila Mariana à assistência à mulher, gestante e criança. $\mathrm{O}$ módulo de Clínica médica tem mantido sua atuação na 
Enfermaria do Hospital São Paulo (HSP), na qual cada aluno é responsável por um leito, sob supervisão docente, cumprindo programação de visitas, discussóes de caso e seminários.

Algumas unidades curriculares dessa série permanecem como disciplinas isoladas, com carga horária prática reduzida, quer por sua característica, especificidade, ou por dificuldades de inserção nos módulos constituídos. As oficinas, seminários e a discussão sobre a avaliação, incluindo a prova de progresso e habilidades e atitudes, constituem subsídios visando a contribuir para o processo de aprimoramento dessas unidades de tal forma que possam se aproximar mais das diretrizes estabelecidas para o projeto pedagógico do curso como um todo.

No Internato, $5^{\underline{a}}$ e $6^{\mathrm{a}}$ séries, predominam as atividades práticas, assumindo o estudante a responsabilidade da assistência direta ao paciente, sempre sob supervisão docente ou de profissionais preparados e designados para esta função de preceptoria. Assim, são desenvolvidas atividades em ambulatórios gerais e de especialidades, em enfermarias, prontos-socorros, sala de parto, centros cirúrgicos do hospital universitário e de hospital geral (nível secundário) do município de São Paulo (Hospital Municipal Vereador José Storopolli-Vila Maria). São também desenvolvidas atividades em unidades básicas de saúde do município do Embu, no cs Lívio Amato-Vila Mariana e, neste ano de 2007, em unidades básicas de saúde do município de São Paulo. $\mathrm{Na} 5^{\underline{a}}$ série, um semestre concentra módulos de especialidades clínicas e cirúrgicas com atividades desenvolvidas no hospital universitário, em sua maioria integradas (exemplo: nefrologia e urologia, gastroclínica e gastrocirurgia). Outro semestre está constituído por módulos de áreas gerais desenvolvidas em unidades básicas de saúde, ambulatórios gerais e multidisciplinares do HSP e no Hospital Vereador José Storopolli - Pediatria geral, ambulatório geral e familiar, Ginecologia, Obstetrícia, como exemplos. $\mathrm{Na} 6^{\underline{a}}$ série, estão incluídos predominantemente os estágios de emergências e de enfermarias gerais, estas desenvolvidas também no Hospital Vereador José Storopolli - Clí- 
nica, Cirurgia, Pediatria, além de algumas especialidades. A crescente especialização e a criação de diferentes serviços exerce sempre uma forte influência sobre o currículo, sobretudo no Internato, gerando intensa discussão junto aos gestores do curso.

\section{A GESTÃO DO CURSO DE MEDICINA NA UNIFESP}

A Comissão do Curso de Medicina está constituída por treze docentes (um deles é o diretor acadêmico do curso) e três estudantes. São quatro professores das $\mathrm{I}^{\underline{\underline{a}}}$ e $2^{\underline{\underline{a}}}$ séries, quatro professores das $3^{\underline{\underline{a}}}$ e $4^{\underline{\underline{a}}}$ séries e quatro professores do Internato ( $5^{\underline{a}}$ e $6^{\mathrm{a}}$ séries). O mandato de cada docente é de dois anos, permitida uma recondução consecutiva, sendo eleito entre seus pares, membros da Sub-comissão correspondente ( $I^{\underline{a}}$ e $2^{\underline{a}}, 3^{\underline{a}}$ e $4^{\underline{a}}$ e Internato). Cada sub-comissão está constituída pelos coordenadores de unidades curriculares e de representantes de cada uma das disciplinas que desenvolvem atividades no curso, nas séries correspondentes. O diretor acadêmico é escolhido pelo próreitor de graduação a partir de uma lista tríplice de docentes membros da Comissão do Curso e eleitos pela referida comissão. O mandato é de dois anos e é permitida uma única recondução consecutiva. A Comissão de Curso conta com comissóes assessoras permanentes para o desenvolvimento de suas atividades: comissão de disciplinas eletivas, comissão da prova do progresso e comissão da prova de habilidades e atitudes e, sempre que necessário, são constituídas comissôes ou grupos de trabalho temporários.

\section{A AVALIAÇÃO DO CURSO DE MEDICINA DA UNIFESP}

As mudanças curriculares mais significativas do curso de Medicina sempre foram precedidas de processos avaliativos. Em 200I, ano de 
edição das Diretrizes Curriculares Nacionais (DCN) para os cursos de graduação em saúde, iniciava-se na Unifesp-EPM um amplo processo de avaliação do Curso Médico, tendo como foco principal as mudanças decorrentes da implantação do Currículo Nuclear em I 997. Com a aprovaçáo do Promed, em 2002, e a complexidade inerente às novas atividades/módulos, a necessidade de acompanhamento e de um processo continuado de avaliação se estabelece definitivamente na instituição. Os acertos necessários e o aprimoramento das atividades se tornaram mais dinâmicos de forma que os módulos deixaram de constituir um currículo rígido, mas sim um caminho, permitindo o re-planejamento ano a ano. A definição de competências - conhecimento, habilidades e atitudes profissionais -, bem como a capacidade para o aprendizado permanente, exigem um novo formato de avaliação, o qual deverá incluir esses componentes. Algumas experiências, sobretudo no que se refere às habilidades e atitudes, vêm sendo adotadas por outras escolas médicas (Troncon, I996; 2004; Ward, 2005). Nesse novo cenário a avaliação tornouse mais complexa, aceitando-se que ela deva fazer parte do processo de ensino-aprendizagem. Além disso, as evidências em pesquisa educacional sugerem que devem ser considerados vários métodos para a avaliação e sua validade está cada vez mais relacionada com sua autenticidade e inserção na prática cotidiana (Silva, 2005). São descritas, a seguir, as estratégias de avaliação implantadas para o Curso Médico da Unifesp - a avaliação do curso pelos estudantes e a avaliação dos estudantes.

\section{A Avaliação do Curso pelos Estudantes Avaliação das Unidades Curriculares/Disciplinas}

Em I 992, a Comissão de Internato iniciou um processo de avaliação de estágios por meio de um instrumento, o qual incluía itens relacionados ao estágio propriamente dito (adequação de atividades em 
relação aos objetivos do curso, carga horária), aos docentes (pontualidade, qualidade das aulas/orientaçôes), à estrutura de ensino (salas de aula, laboratórios, consultórios, enfermarias, exames subsidiários) e auto-avaliação. Esse instrumento foi expandido com adaptaçôes para as demais séries e, posteriormente, para todos os cursos. Foi criada uma comissão de avaliação para sua condução e aplicação do instrumento no final das disciplinas/estágios, por amostragem. Em 2000, foi implantado o sistema on-line, facilitando a sua operacionalização. Têm sido gerados relatórios, que são discutidos e analisados pelos gestores de curso (comissóes e sub-comissóes) e encaminhados também às chefias de departamentos, disciplinas e coordenadores das unidades curriculares.

\section{A Avaliação do Curso e do Estudante de Medicina A Prova do Progresso e a Avaliação de Habilidades e Atitudes}

A Prova do Progresso foi implantada na Unifesp no ano de 1997 (Borges \& Stella, I 999). A partir de 2003, uma comissão assessora da Comissão do Curso Médico (CCM), constituída por representantes docentes de departamentos de grandes áreas e de departamentos das áreas biológicas - Pediatria, Clínica, Ginecologia, Obstetrícia, Medicina Preventiva, Cirurgia, Psiquiatria e Biológicas - passou a coordenar a elaboração, a aplicação e a análise desses dados. Seus resultados têm sido discutidos na ССм e sub-comissóes e nos departamentos acadêmicos, trazendo subsídios para o aprimoramento do curso. Desde 2005, a Unifesp passou a integrar o Núcleo Interinstitucional de Avaliação do Ensino Médico, integrado por escolas médicas do Estado de São Paulo e Santa Catarina. Esse núcleo tem realizado uma prova de progresso única, elaborada e analisada em conjunto e contribuiu para o aprimoramento do processo de avaliação na instituição. Alguns desafios, em ambos os processos, ainda não foram superados, destacando-se a pouca participação dos estu- 
dantes das primeiras séries dos cursos, a devolutiva para o estudante, o envolvimento mais amplo dos docentes que atuam no curso na discussão dos resultados dessa prova.

Com o objetivo de avançar no processo de avaliação do Curso de Medicina e considerando o momento de profundas discussóes em relação à formação do médico, em 2005 foi criada a Comissão de Avaliação de Habilidades e Atitudes, constituída por docentes representantes de departamentos de grandes áreas e/ou com interface com as mesmas - Clínica, Pediatria, Ginecologia-Obstetrícia, Cirurgia, Ortopedia, Saúde Coletiva e Psiquiatria. Precedendo a realização dessa primeira experiência, foi organizado um seminário sobre avaliaçáo de competências, foram discutidos artigos e documentos sobre o tema, realizadas visitas a instituições que já realizavam avaliação de habilidades e atitudes, e houve ainda um incentivo à participação de professores nos eventos regionais e nacionais de educação médica que têm abordado a questão da avaliação.

Em novembro de 2006 foi realizada a primeira prova da Unifesp dirigida aos estudantes de $5^{\underline{a}}$ série, visando à possibilidade de recuperação para alunos que apresentassem dificuldades. A elaboração dessa prova exigiu a definição de competências por grande área em reuniōes realizadas junto aos respectivos departamentos - Pediatria, Clínica, Ginecologia, Obstetrícia, Cirurgia e Saúde Coletiva, definindo-se que a Psicologia Médica e a Saúde Coletiva deveriam integrar-se com as demais áreas nesta primeira experiência de aplicação da prova. Posteriormente, devido ao processo de discussão interna no Departamento de Medicina Preventiva, decidiu-se aprofundar essa discussão em relaçáo à saúde coletiva para o próximo ano. A prova constou de dois momentos: I) nas enfermarias do HSP, com pacientes internados e a avaliação realizada mediante um roteiro de observação elaborado por docentes dos departamentos de medicina e cirurgia. Participaram 54 professores (um a dois estudantes por professor) e foram avaliadas competências da área clínica de adulto; 2) estruturado em estaçóes 
(bonecos, atores e atrizes), foram avaliadas competências das áreas de Pediatria, Ginecologia, Cirurgia e Obstetrícia. Participaram 38 professores, 27 profissionais técnico-administrativos (atores, atrizes, apoio) e cinco residentes, num total de setenta pessoas. Houve grande receptividade dos estudantes e a devolutiva para os estudantes constou da apresentaçáo pelos professores de cada questão da prova, principais dificuldades e acertos. Foram identificados pontos para seu aprimoramento, porém seus resultados chamaram a atenção de docentes em relação à necessidade de avaliação prática sistematizada no decorrer do curso, sobretudo na unidade curricular Semiologia humana e nos estágios do Internato, além de favorecer o constante processo de definição de competências de cada área e, conseqüentemente, reprogramação dos estágios.

\section{O CURRÍCULO DE MEDICINA DA UNIFESP}

UM PROCESSO DE PERMANENTE CONSTRUÇÃO

O currículo do curso de Medicina da Unifesp tem sido continuadamente avaliado e aprimorado. Nos últimos anos, ficou claro para o corpo docente que as mudanças são necessárias e que um currículo rígido não tem mais lugar no atual momento, considerando os avanços tecnológicos da área, o atual sistema de saúde, seu dinamismo e as conquistas de nossa sociedade, notadamente a saúde como direito e o controle social. A possibilidade de o estudante buscar conhecimento e se inserir em diferentes projetos - pesquisa, assistência e extensão - enriquecem a sua formação e favorecem vivências que certamente deverão influenciar escolhas e desempenho profissional. 


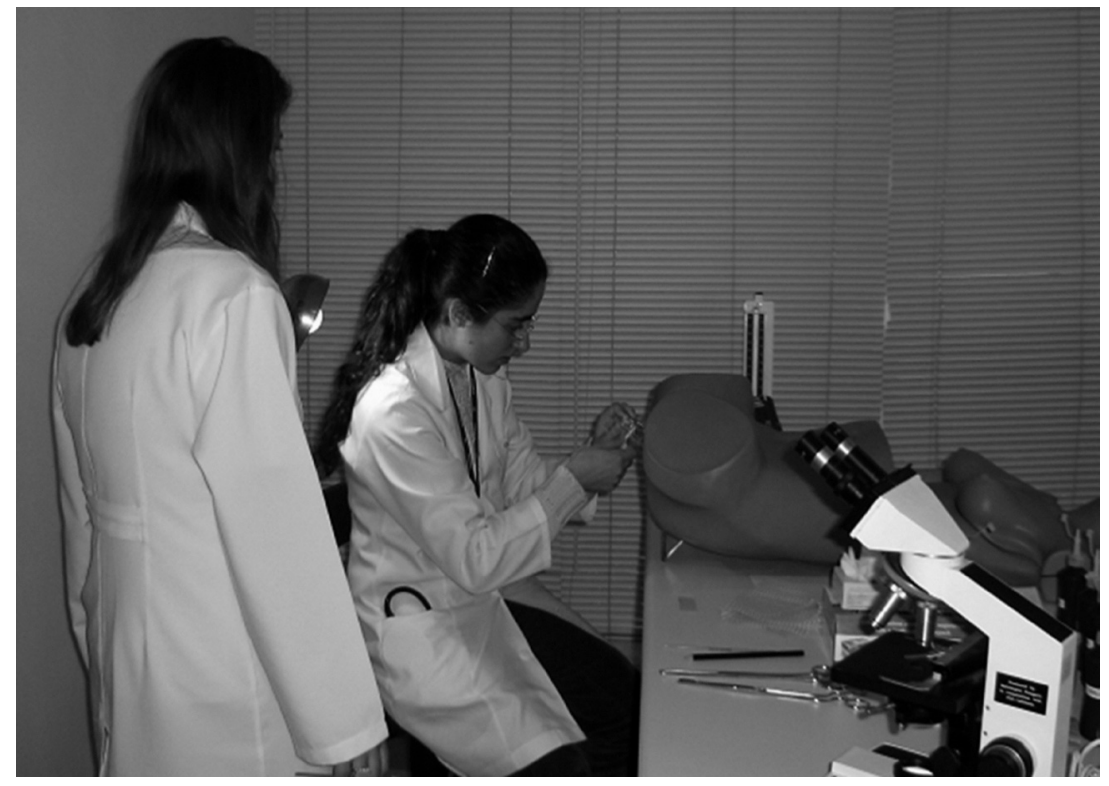

Figura I. Prova de Ginecologia, 2006.

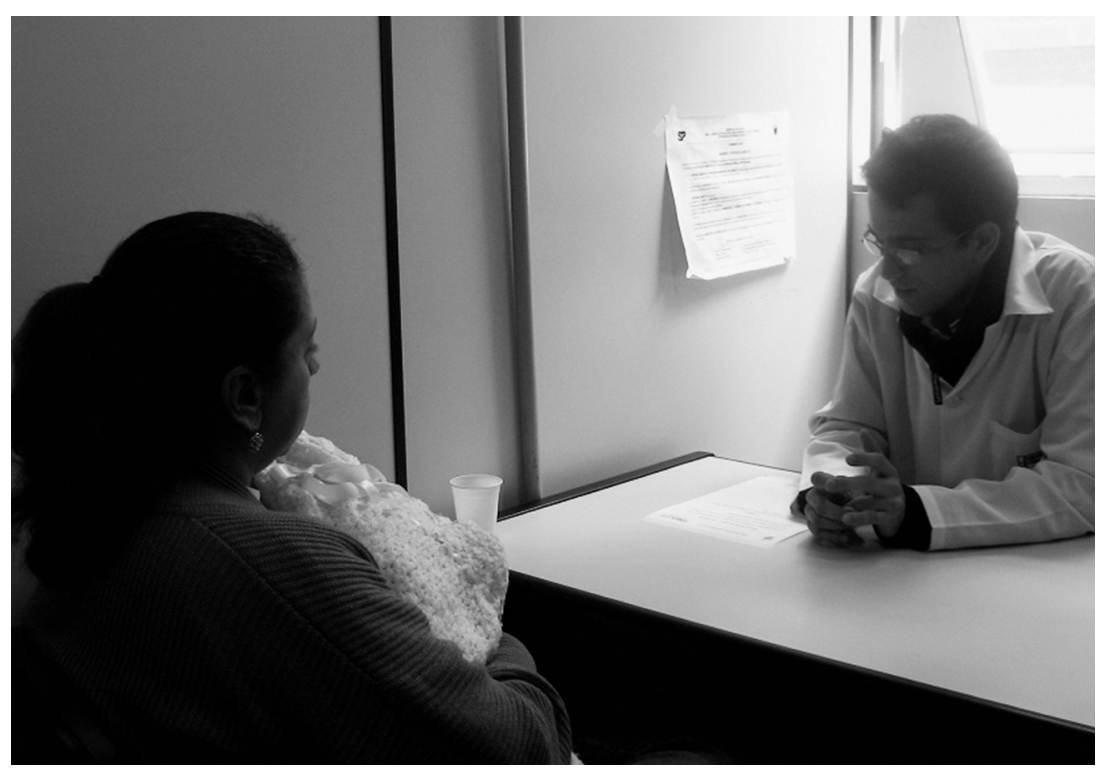

FIgURA 2. Prova de Pediatria, 2006. 


\section{REFERÊNCIAS BIBLIOGRÁFICAS}

Brasil. 200i. Ministério da Educação. Conselho Nacional de Educação. Câmara de Educação Superior. Diretrizes Curriculares Nacionais do Curso de Graduação em Medicina Resolução CNE/CES no 4. Brasília (DF), 4 nov.

Brasil. 2002. Ministério da Educação. Ministério da Saúde. Programa de Incentivo a Mudanças Curriculares nos Cursos de Medicina - Promed. Portaria Interministerial no 6 Io. Brasília (DF), 26 mar.

Borges, D. R. \& Stella, R. C. R. i 999. "Avaliação do Ensino de Medicina na Universidade Federal de São Paulo”. Rev. Bras. Educ. Med., 23, pp. I I-I 7 .

Chaves, M. \& Rosa, A. R. I990. Educação Médica nas Américas: o Desafio dos Anos 9o. São Paulo, Cortez Editora.

Comıssão Interinstitucional Nacional de Avaliação do Ensino Médico (Cinaem). 2000. Preparando a Transformação da Educação Médica: Relatório 1999-2000.

Feuerwerker, L. C. M. 2006. "O Movimento Mundial de Educação Médica: As Conferências de Edimburgh". Cadernos da ABEM: Coletânea de Artigos Originais e Publicados nos Boletins Informativos da ABEM, 2, pp. 30-38.

Marco, M. A. 2007. A Face Humana da Medicina - do Modelo Biomédico ao Modelo Biopsicossocial. $2^{\underline{a}}$ ed., São Paulo, Casa do Psicólogo.

Silva, F. A. M. 2005. "Desafios para 2006 no Campo da Avaliação das Escolas Médicas”. Rev. Bras. Educ. Med., 29, pp. I 59-160.

Siqueira, B. P. 2006. "Cinaem - um Pouco de História”. Cadernos da ABEM: Coletânea de Artigos Originais e Publicados nos Boletins Informativos da $A B E M, 2$, pp. 54-56.

Stella, R. C. R. \& Campos, J. J. B. 2006. "Histórico da Construção das Diretrizes Curriculares na Graduação em Medicina no Brasil". Cadernos da ABEM: Coletânea de Artigos Originais e Publicados nos Boletins Informativos da ABEM, 2, pp. 73-77.

Troncon, L. E. A.; Foss, N. T. \& Voltarelli, J. C. i996. "Avaliação de Habilidades Clínicas por Exame Objetivo Estruturado por Estações, com 
Emprego de Pacientes Padronizados: uma Aplicaçáo no Brasil”. Rev. Bras. Educ. Méd., 20, pp. 53-60.

Troncon, L. E. A. 2004. "Clinical Skills Assessment: Limitations of an osce

(Objective Structures Clinical Examination) in a Traditional Brazilian Medical School”. Med. J., São Paulo, I22, pp. I2-I7.

Ward, L. S.; Wanderley, J. S. \& Alegre, S. M. 2005. "Implantação de um Sistema de Avaliação Estruturada de Performance em Escola Médica: Resultados do Projeto-piloto". Rev. Bras. Educ. Méd., 29, pp. I74-178.

World Federation of Medical Education. 1988. World Conference on Medical Education Report. Edimburgh. 
